Article

\title{
Optically Pumped Intensive Light Amplification from a Blue Oligomer
}

\author{
Mamduh J. Aljaafreh ${ }^{1}$, Saradh Prasad ${ }^{1,2}{ }^{(0}$, Mohamad S. AlSalhi ${ }^{1,2, *} \mathbb{C}$, Zeyad A. Alahmed $^{1}$ and \\ Muneerah M. Al-Mogren ${ }^{3}$ \\ 1 Department of Physics and Astronomy, College of Science, King Saud University, \\ Riyadh 11451, Saudi Arabia; maljaafreh@ksu.edu.sa (M.J.A.); saradprasad@gmail.com (S.P.); \\ zalahmed@ksu.edu.sa (Z.A.A.) \\ 2 Research Chair on Laser Diagnosis of Cancers, Department of Physics and Astronomy, College of Science, \\ King Saud University, Riyadh 11451, Saudi Arabia \\ 3 Chemistry Department, Faculty of Science, King Saud University, P.O. Box 2455, Riyadh 11451, Saudi Arabia; \\ mmogren@ksu.edu.sa \\ * Correspondence: malsalhi@ksu.edu.sa; Tel.: +966-50-510-4815
}

Received: 21 August 2019; Accepted: 13 September 2019; Published: 20 September 2019

\begin{abstract}
We demonstrated the time-resolved dynamics of laser action from the conductive oligomer (CO) 1,4-Bis(9-ethyl-3-carbazo-vinylene)-9,9-dihexyl-fluorene (BECV-DHF). Absorption and fluorescence spectra were studied for BECV-DHF in different solvents under a wide range of concentrations. The Fourier-transform infrared spectroscopy (FTIR) spectrum was measured using simulation and experiments. The Ultraviolet-Visible (UV-VIS) spectra of the BECV-DHF were simulated in two different solutions. This $\mathrm{CO}$ formed a dimer and had two vibration bands in nonpolar solvents, partially dissolved in polar protic solvents, and created an $\mathrm{H}$-type aggregate in polar aprotic solvents. BECV-DHF produced amplified spontaneous emission (ASE) at $464 \mathrm{~nm}$ in many solvents. The high efficiency of ASE is due to the waveguiding and self-assembly nature of the oligomer, which is very rare for optically pumped systems. However, BECV-DHF did not produce ASE in polar protic solvents. BECV-DHF produced ASE in both longitudinal and transverse pumping, and the full-width half maximum (FWHM) was $4 \mathrm{~nm}$ and $8 \mathrm{~nm}$ respectively for different solvents, such as toluene and acetone. The CO had a very low threshold pump energy $(\sim 0.5 \mathrm{~mJ})$. The ASE efficiency was approximately $20 \%$. The time-resolved spectroscopy (TRS) studies showed a temporal Gaussian-shaped ASE output from this CO. BECV-DHF shows remarkably high stability compare to the conjugated polymer (CP) PFO-co-pX.
\end{abstract}

Keywords: TD-DFT; conductive oligomer (CO) 1,4-Bis(9-ethyl-3-carbazo-vinylene)-9,9-dihexyl-fluorene (BECV-DHF); amplified spontaneous emission (ASE); time resolved spectroscopy (TRS)

\section{Introduction}

A material must possess various unique properties in order to be beneficial as a laser gain medium [1,2]. Foremost, the electronic structure for the material has to contain at least a two-level (or best a four-level) system such as a ruby crystal (conjugated polymers), so that the emission of these materials does not overlap with the absorption spectrum [2,3]. High luminescence and chromophore density are considered to be necessary conditions for laser gain materials; many conjugated materials stand out in this respect [4]. However, at high concentrations, the photoluminescence efficiencies drop for conjugated polymer laser chromophores, despite having the remarkable properties above. Another crucial property of any gain medium is that it must show a large cross-section stimulated emission, which is nominally in the range of $\sigma=10^{-15} \mathrm{~cm}^{2}$ for conjugated polymers [5,6]. This factor can affect 
laser action in terms of maximum gain, since the gain coefficient of the laser material $(g=n \sigma)$ depends on $\sigma$ and the density of electrons in the excited state (n).

The extraordinary photophysical properties of organic semiconductor materials have attracted a great deal of interest [2,7-9]. Conjugated materials have become highly desired materials for photonics devices, namely, light-emitting diodes [10,11], solar cells [12,13], organic field-effect transistors [14,15], and optical gain media, especially for lasers [16-19]. However, conjugated polymers (CPs) suffer from some disadvantages such as conformation irregularities, aggregation, low solvent solubility, uncontrollable polydispersity, and batch-to-batch irregularities. These disadvantages can be overcome in conductive oligomers (COs), in which significant advantages, such as a well-defined chemical structure, high self-aligning capabilities, chemical purity, and photophysical stability, are realized. However, the boundary between COs and CPs is not well defined, since the performance of the oligomers matches or exceeds the performance of the $\mathrm{CP}$ counterparts. Oligomers are a material that has a low molecular weight and contains a small number of repetitive units and a regular repeating structure (monodispersity and regioregular) [20-22]. Over the past decades, many detailed research papers have reported the amplified spontaneous emission (ASE) and the light amplification of oligomers [23-26]. ASE is considered to be a mirrorless laser, since most of the photons emitted are due to stimulated emission, and significant amplification is possible in a single pass [27]. Most of the organic semiconducting materials produce mirrorless lasers through a single trip of the laser light. When resonant feedback is combined with the $\mathrm{CP}$ or $\mathrm{CO}$ gain medium, it converts the ASE into an actual laser.

The ASE and spectral properties of the oligomer 9,9, $9^{\prime}, 9^{\prime}, 9^{\prime \prime}, 9^{\prime \prime}$-hexakis(octyl)-2, $7^{\prime}, 2^{\prime}, 7^{\prime \prime}$-trifluorene (HOTF) under pulsed laser excitation in solution were studied [23]. The time-resolved spectroscopy of ASE from the conjugated oligomer 9,10-Bis[(9-ethyl-3-carbazoyl)-vinylenyl]-anthracene (BECVA) was reported only upon energy transfer [28]. Features of the unusually narrow emission from hexagonal 2,5-bis(4-biphenylylthiophene (BP1T) crystals were demonstrated under a line laser beam as the excitation source [29]. Lasing from single crystals of 2,5-bis(4'-cyanobiphenyl-4-yl)thiophene (BP1T-CN) was observed at room temperature. The results showed that the BP1T-CN crystal is an excellent gain medium, depending on high values of the group refractive index $n_{g}(4.18-4.98)$ and high Q factor (910-1860) [30].

In this work, we report the spectral and laser properties of the CO 1,4-Bis(9-ethyl-3-carbazovinylene)-9,9-dihexyl-fluorene (BECV-DHF) in different solvents under pulsed laser excitation in both transverse and longitudinal excitation. The molecular structure optimization and UV-VIS calculations, Highest Occupied Molecular Orbital (HOMO) - Lowest Unoccupied Molecular Orbital (LUMO) energies, FTIR, absorption wavelengths, and oscillator strengths are theoretically analyzed and obtained by using the Time-dependent density functional theory/Becke, 3-parameter, Lee-Yang-Parr (TD-DFT/B3LYP) method with 6-31G $(\mathrm{d})$ and $6-31 \mathrm{G}^{*}(\mathrm{~d}, \mathrm{p})$ basis sets using Gaussian 09 [31]. The theoretical and experimental results presented are in good agreement with each other. Additionally, we show that under sufficient concentration and low pump energy, BECV-DHF can produce ASE at $464 \mathrm{~nm}$ in a large number of solvents. The ASE conversion efficiency was approximately $20 \%$. A temporal Gaussian-shaped ASE output from this CO was noted through the time resolved spectroscopy (TRS) studies.

\section{Materials and Methods}

Figure 1 shows the planar molecular structure the optimized geometric structure of the CO BECV-DHF, which is comparable with poly(o-phenylenediamine) oligomers [32] and Poly[(9,9-dioctylfluorenyl-2,7-diyl)-co-(4,4'-(N-(4-sec-butylphenyl)diphenylamine)] (TFB) polymer structures [33]. The molecule consists of a central core with 9,9-dihexyl-9H-fluorene with two 9-ethyl-9H-carbazoles on either side attached through (2E)-but-2-ene arms. It contains two long-chain hexane substituents on the fluorene core, which makes the material soluble in nonpolar solvents, and the carbazoles on either side have a high polarity that makes it soluble in polar solvents with excellent 
film-forming properties (as shown in Supplementary Figure S1a,b). This CO has many conformations, but Figure 1b,c shows the conformation with the lowest energy. Hence, the conformation in Figure 1b,c was chosen for simulation purposes.

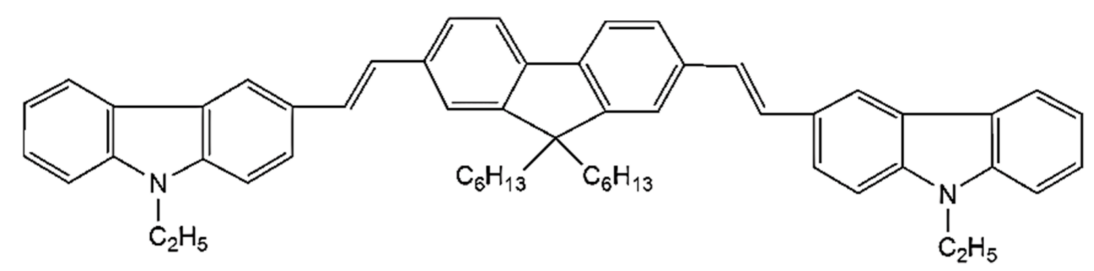

(a)

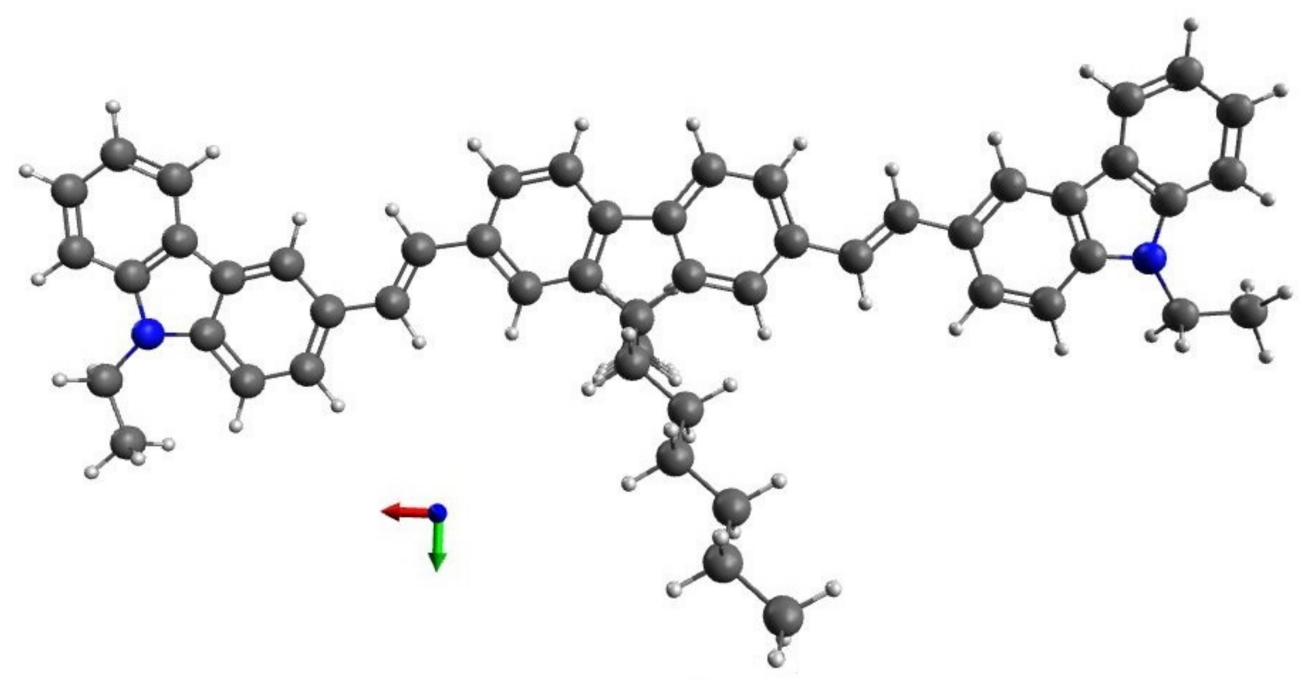

(b)

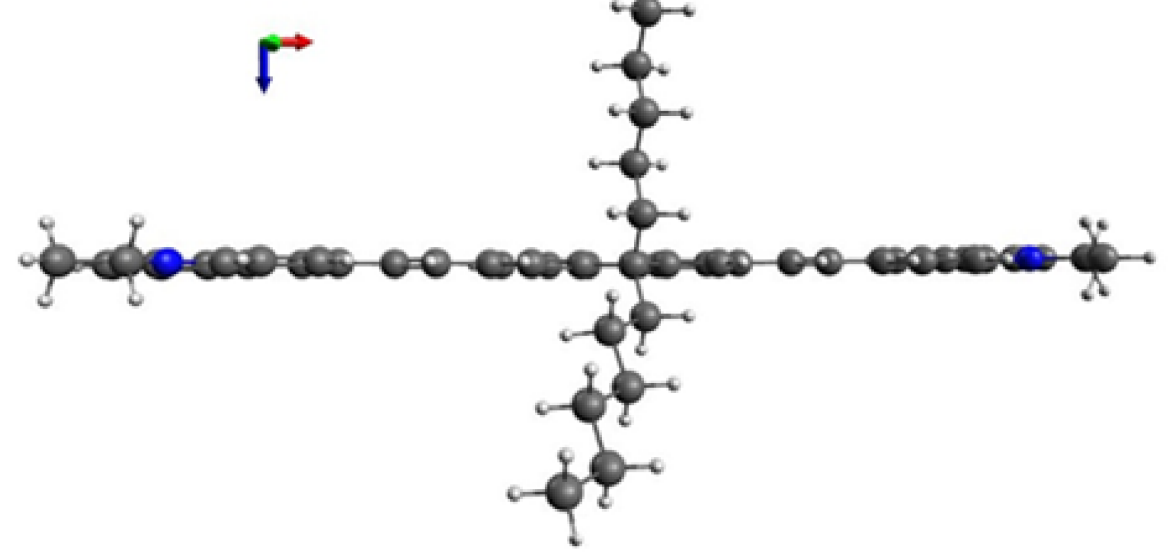

(c)

Figure 1. (a) The molecular structure of conductive oligomer (CO) 1,4-Bis(9-ethyl-3-carbazovinylene)-9,9-dihexyl-fluorene (BECV-DHF), (b) optimized geometry top view, and (c) bottom view using DFT calculation using universal force field (UFF) stepwise descent (Avogadro 1.1.1) and then using B3LYP/6-31G(d) (Gaussian 09). 
The CO had a molecular weight of $773.12 \mathrm{~g} \mathrm{~mol}^{-1}$, and CP poly[(9,9-dioctylfluorenyl2,7-diyl)-co-(2,5-p-xylene)] (PFO-co-pX) had a molecular mass of 120,000 GPa (for molecular structure, please see [19]). They were imported from American Dye Source, Inc. (Quebec, QC, Canada). The spectroscopic grade solvents acetone, benzene, methanol (meth), dimethylformamide (DMF), and toluene were purchased from Sigma Aldrich. The TD-DFT calculations were done using Gaussian 09. For initial optimization, the open-source software Avogadro 1.1.1 was utilized. An advanced attenuated total reflectance (ATR) instrument with a range of $550-4000 \mathrm{~cm}^{-1}$ was used to investigate the FTIR spectra of the CO BEVH-DHF. The ATR used for the FTIR experiment was a Perkin Elmer Spotlight 150i (Llantrisant, UK). A Perkin Elmer Lambda 950 spectrophotometer (Llantrisant, UK) was used to measure the absorption spectra across the 100-1100 nm range, and a spectrofluorometer (LS 55, from the same company) was utilized to measure the fluorescence spectra through a scan range of 200-1000 nm at room temperature. An energy meter was used to measure the input and output energy from the samples.

The laser source for optical pumping was set to $5 \mathrm{~ns}$ pulse, $355 \mathrm{~nm}$ (frequency tripled Nd:YAG). The pump pulse from the Nd:YAG laser was focused by a $5 \mathrm{~cm}$ focal length quartz cylindrical lens (for transverse pumping) or spherical lens (for longitudinal pumping). The focused pulse with a shape line or cone was applied to excite the CO solutions. The CO solution produced laser-induced fluorescence (LIF) and ASE under suitable pump energies. The output light was fed to an optical fiber connected to an ultrafast camera (Princeton Instruments PI MAX 4 with an Acton spectrograph). The light signal was fed to a spectrograph with a linear array charge-coupled device (CCD) (Ocean Optics Spectroscopy, USB4000-XR1-ES, Ostfildern, Germany) to record the spectral features.

\section{Results and Discussion}

\subsection{FTIR Investigation}

Figure 2 shows the FTIR spectrum of the CO BECV-DHF simulated (blue) using TD-DFT with the Becke three-parameter Lee-Yang-Parr B3LYP/6-31G* $(\mathrm{d}, \mathrm{p})$ basis set and experimental (orange) results measured using the FTIR instrument. The peak at approximately $3210-3220 \mathrm{~cm}^{-1}$ is due to stretching of the $\mathrm{C}-\mathrm{H}$ bond in the aromatic rings $(\mathrm{C} 10-\mathrm{H} 68, \mathrm{C} 9-\mathrm{H} 67)$ as presented in Figure S2. The peak at approximately $2916 \mathrm{~cm}^{-1}$ is due to stretching of the C-H bond at the tail of the atom (C57-C62, with H atoms). The peak at approximately $1230-1240 \mathrm{~cm}^{-1}$ is due to stretching of the $\mathrm{C}-\mathrm{C}$ bond in the aromatic ring and due to bending of the $\mathrm{C}-\mathrm{H}$ bond at the tail of the atom as shown in Figure S3. The peak at approximately $742 \mathrm{~cm}^{-1}$ represents the stretching of the $C-C, C=H$ bonds in the ring, as demonstrated in Figure S4. The computational simulation and the experimental result were in agreement. For example, the longer wavelength peak at $2916 \mathrm{~cm}^{-1}$ in the experimental spectra is matched with $2929 \mathrm{~cm}^{-1}$ in the simulation, which indicates that a discrepancy between them is less than $1 \%$. Note that a scaling factor was not used. The experimentally measured and simulated FTIR results showed a very close match, which confirms that the simulation method adopted for this $\mathrm{CO}$ is accurate. 


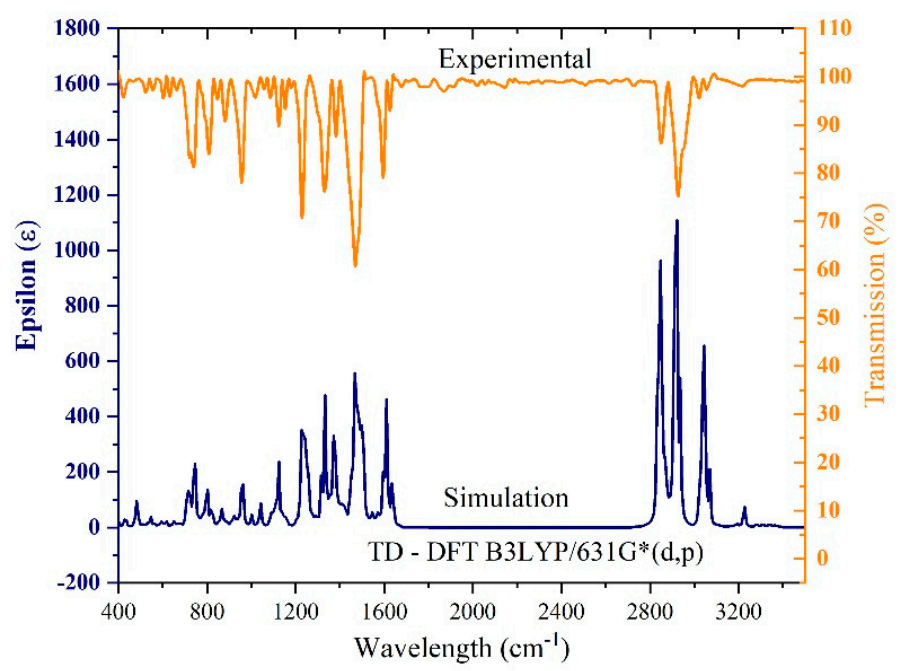

Figure 2. Simulated and experimental FTIR spectrum.

\subsection{Time-Dependent DFT Calculation of HOMO-LUMO}

The molecular orbitals provide great insight into electronic structures and are broadly used in the investigation of chemical reactions and physical properties. Figure $3 \mathrm{a}, \mathrm{b}$ shows the HOMO-LUMO structure of the CO BECV-DHF calculated using TD-DFT with the B3LYP functional and 6-31G* $(\mathrm{d} . \mathrm{p})$ basis set. The geometry optimization and HOMO-LUMO structure were computed for CO under toluene and acetone cavitation. In toluene, as shown in Figure 3a, the HOMO-LUMO structure shows that the 9,9-dihexyl-9H-fluorene segment A contributed to the chromophore and that the 9-ethyl-9H-carbazole segments B have a little influence. In another study, we showed that a similar molecular structured CP PFO had an absorption peak at $360 \mathrm{~nm}$, in which the 9,9-dioctyl-9H-fluorene segment was the entire contributor to the chromophore. Hence, the redshift of the absorption spectrum peak (398 nm) in BECV-DHF when compared to PFO is due to the contribution from Segment B. The long tail in segment A (i.e., 9,9-dihexyl) does not contribute to the fluorescence but could be the reason for the aggregation [34]. One can note that the LUMO contains a grouping of bonding orbitals for the $\mathrm{C}-\mathrm{C}$ chemical bonds oriented along the long axis direction, while the HOMO contains a combination of bonding orbitals for $\mathrm{C}-\mathrm{C}$ chemical bonds oriented along the short axis, which can be seen in other conjugated materials [35].

The HOMO-LUMO structure of the CO BECV-DHF for acetone cavitation was calculated using TD-DFT with the B3LYP/6-31G* $(d, p)$ basis set as presented in Figure $3 \mathrm{~b}$. The contour of the HOMO is same in acetone when compared to toluene, except that segment $\mathrm{B}$ (9-ethyl-9H-carbazole) has more electron density. The computed HOMO-LUMO gap is consistent with the experimental results of $\mathrm{CO}$ in the two solvents, as in Figure $4 \mathrm{a}, \mathrm{b}$. The energy gap $\left(\mathrm{E}_{\mathrm{g}}\right)$ of the $\mathrm{CO}$ was found from the derivative of transmission and calculated using the relation $\mathrm{E}_{\mathrm{g}}=\mathrm{hc} / \lambda_{\max }$. The derivative of transmission over the photon wavelength $(\mathrm{dT} / \mathrm{d} \lambda)$ peak corresponded to the bandgap of the $\mathrm{CO}$. The difference in the simulated and observed bandgap is because the experimental bandgap is obtained for a group of $\mathrm{CO}$ molecules in a large volume of solution, but computation is based on a single molecule with solutions cavitation. However, the difference is in an acceptable range. The results reveal that the $\lambda_{\max }$ for $\mathrm{CO}$ in toluene and acetone (for the same concentration of $1.235 \mu \mathrm{M}$ ) was 431 and $427.47 \mathrm{~nm}$, respectively. The band gaps corresponding to these wavelengths were $2.877 \mathrm{eV}$ and $2.901 \mathrm{eV}$, respectively, as shown in Figure $4 \mathrm{a}, \mathrm{b}$, with a discrepancy of $7.4 \%$ and $9.85 \%$ when compared to the stimulation. It is also possible to find the $\mathrm{CO}$ optical energy gap by crossing the absorption and fluorescence spectra for $1.235 \mu \mathrm{M}$ in the same solvents with $\mathrm{Eg}=2.877 \mathrm{eV}$ in toluene and $\mathrm{Eg}=2.897 \mathrm{eV}$ in acetone, as presented in Figures S5 and S6. 


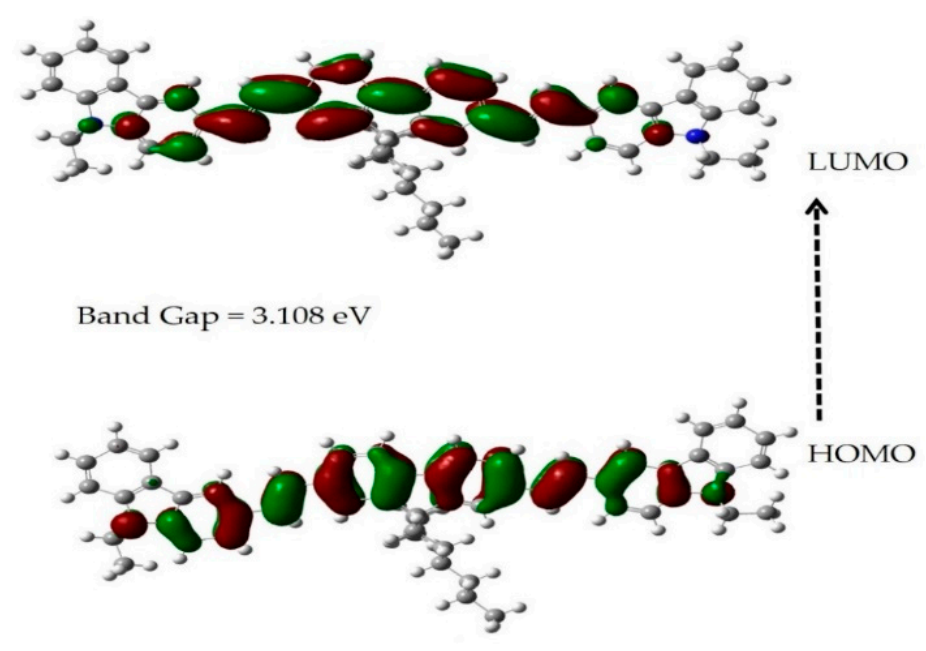

(a)

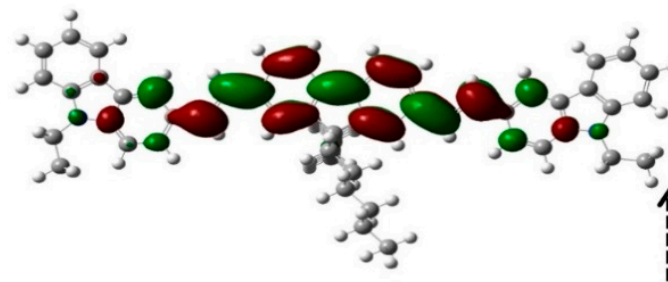

Band Gap $=3.218 \mathrm{eV}$

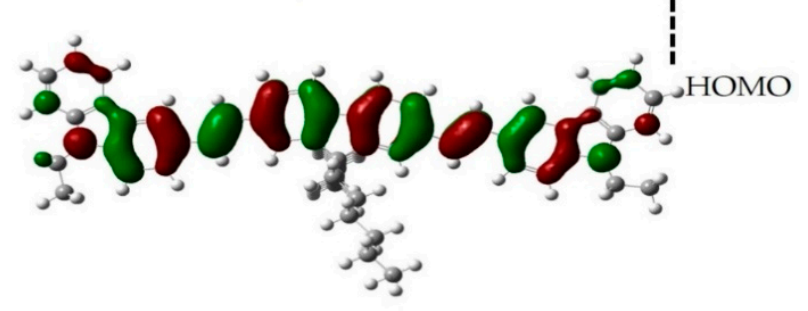

(b)

Figure 3. The HOMO-LUMO structure of CO BECV-DHF calculated using TD-DFT with B3LYP/6-31G* $(\mathrm{d}, \mathrm{p})$ basis set $(\mathbf{a})$ toluene and $(\mathbf{b})$ acetone cavitation.

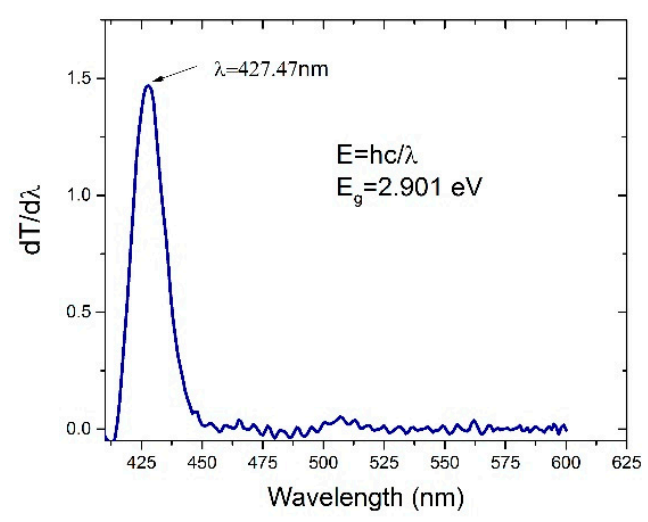

(a)

Figure 4. Cont. 


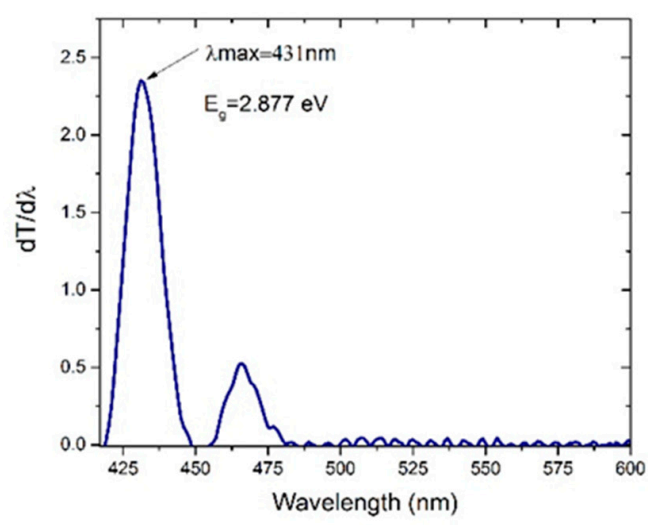

(b)

Figure 4. The variation of $\mathrm{dT} / \mathrm{d} \lambda$ vs. wavelength $\mathrm{CO}$ in (a) acetone and (b) toluene.

\subsection{Time-Dependent DFT of CO's Energies}

Figure 5a shows the simulated and experimental spectral profile of BECV-DHF in toluene. The simulation was done using TD-DFT with the B3LYP/6-31G* $(\mathrm{d}, \mathrm{p})$ (green line) basis sets and toluene cavitation. The experimental spectrum was measured at a low concentration $(7.58 \mu \mathrm{M})$ of $\mathrm{CO}$ in toluene. The oscillator strength and absorbance serve the same purpose because the oscillator strength is utilized as a scale of the relative strength of the electronic transitions within the molecular and atomic systems. The simulation based on B3LYP/6-31G* $(\mathrm{d}, \mathrm{p})$ gave only one peak at $389 \mathrm{~nm}$, with an oscillator strength (f) of 2.1718. The theoretically simulated $\lambda_{\max }$ at $395 \mathrm{~nm}$ showed a strong correlation with the experimental $\lambda_{\max }$ at 398 with a $3 \mathrm{~nm}$ difference. The full-width half-maximum (FWHM) of the experimental results $(\sim 67 \mathrm{~nm})$ was narrower than that of the simulated spectrum $(\sim 79 \mathrm{~nm})$. Figure $4 \mathrm{~b}$ shows the experimental absorption spectrum (blue line) of a low concentration $(7.58 \mu \mathrm{M})$ of $\mathrm{CO}$ in acetone and the simulated absorption spectrum (green line) of $\mathrm{CO}$ in an acetone cavity using B3LYP/6-31G* $(\mathrm{d}, \mathrm{p})$ as the basis set. The simulated spectrum contained one peak at $415 \mathrm{~nm}$ with an oscillator strength (f) of 2.526, which is the closest compared to the experimental absorption band at $415 \mathrm{~nm}$ and has a variation of 20 with the experimental $\lambda_{\max }$ at $395 \mathrm{~nm}$. The FWHM of the simulated spectrum $(\sim 81 \mathrm{~nm})$ was comparable to the experimental results $(\sim 80 \mathrm{~nm})$. The simulation shows that the oscillator strength of $\mathrm{CO}$ in nonpolar and polar solvents was high and almost equal.

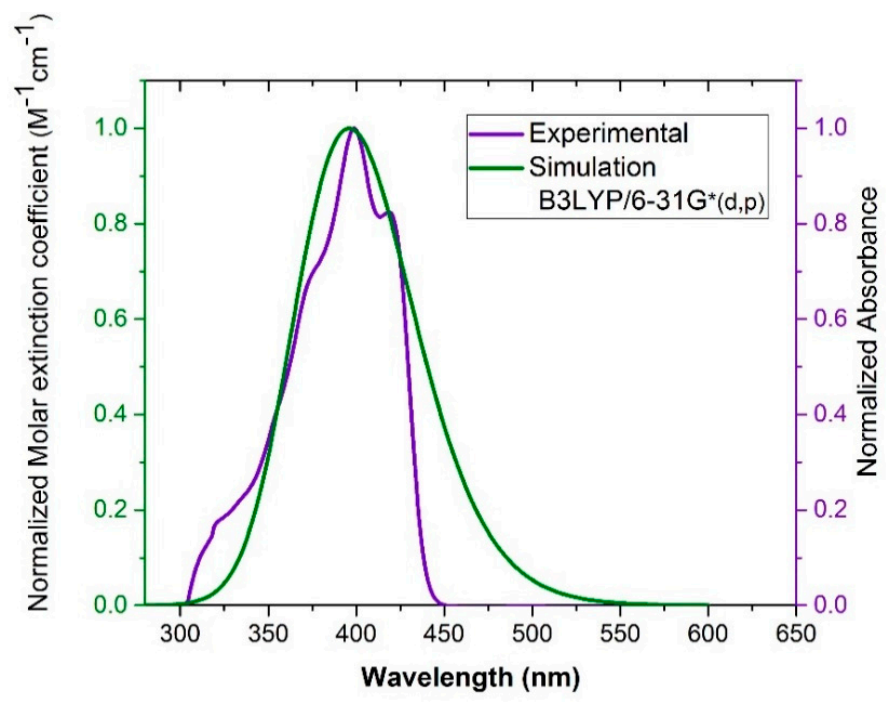

(a)

Figure 5. Cont. 


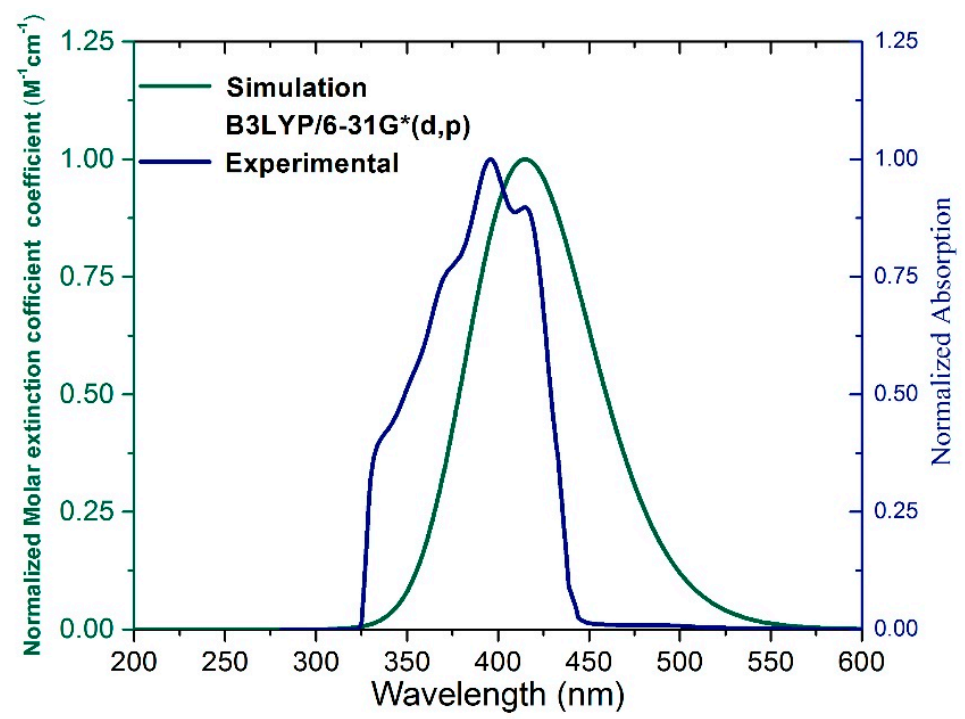

(b)

Figure 5. Comparison of the simulation and experimental absorption spectra in (a) toluene and (b) acetone.

\subsection{Experimental Absorption Spectra in Solution}

Figure 6a shows the absorption spectra for three different solvents, where the blue line is the spectral profile of CO in methanol (a polar protic solvent), with a peak at $393 \mathrm{~nm}$ and two humps at approximately 371 and $409 \mathrm{~nm}$ on either side of the peak, and the FWHM was $66.5 \mathrm{~nm}$. The green line is the spectral profile of CO in DMF (a polar aprotic solvent), with a peak at $400 \mathrm{~nm}$ and humps at approximately 374 and $421 \mathrm{~nm}$, and the FWHM was $78.6 \mathrm{~nm}$. In addition, the red line is the spectral profile of $\mathrm{CO}$ in benzene (a nonpolar solvent), with a peak at $400 \mathrm{~nm}$ and humps at approximately 373 and $421 \mathrm{~nm}$, and the FWHM was $70 \mathrm{~nm}$. The absorbance spectra of the polar aprotic and nonpolar solvents showed a very similar profile with well distinguishable peak and humps, but for the polar protic solvent spectra are slightly shifted in relative to other solutions and the profile was narrow as well as the features were distinctive. The hump at $373 \mathrm{~nm}$ is due to vibronic band S0-S1 of monomer, the peak at 400 is due to vibronic band S0-S2 of monomer, and the hump at $421 \mathrm{~nm}$ is attributed to the dimer. Section 3.5 describes these two humps and the peak.

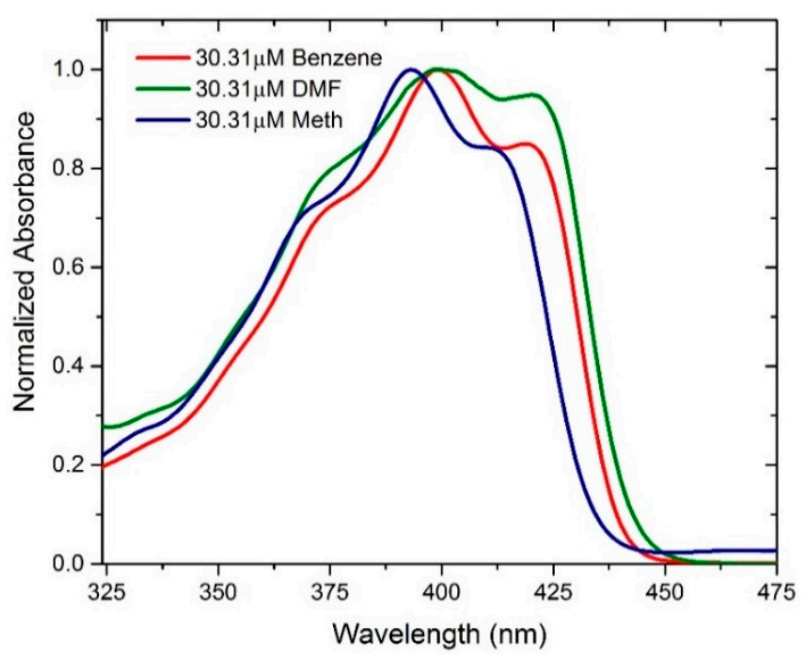

(a)

Figure 6. Cont. 


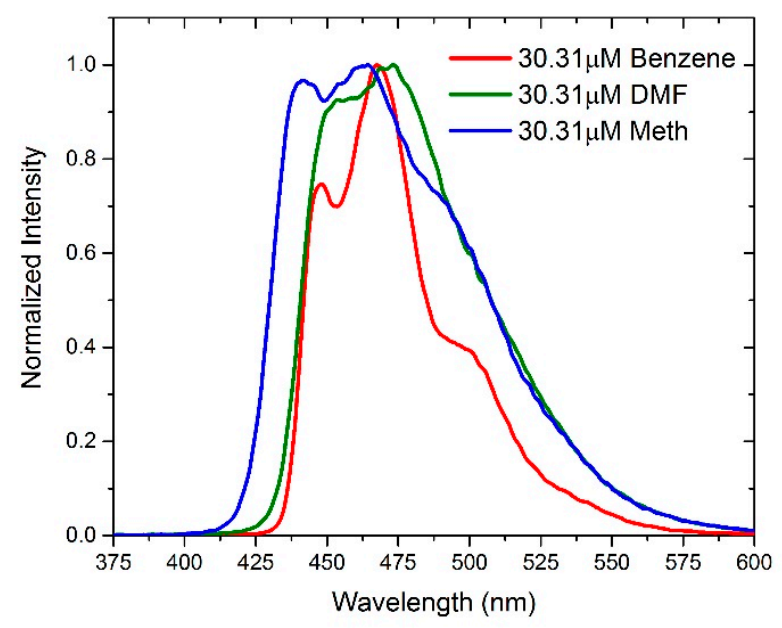

(b)

Figure 6. (a) Absorption and (b) fluorescence spectra of BECV-DHF in three different solvents at a concentration of $30.31 \mu \mathrm{M}$.

The fluorescence spectra for three different solvents specified is given in Figure $6 \mathrm{~b}$. The interval between the peaks in the fluorescence spectra in the three solvents is analogous to the three features in the absorption spectra. The fluorescence profile of $\mathrm{CO}$ in methanol had two peaks at 441 and $463 \mathrm{~nm}$ along with a hump in the longer wavelength region at approximately $486 \mathrm{~nm}$; the fluorescence FWHM was $77 \mathrm{~nm}$. The spectra of CO in DMF had a hump at approximately $455 \mathrm{~nm}$ and a peak at $473 \mathrm{~nm}$ with an FWHM of $68 \mathrm{~nm}$. The profile of CO in benzene (a nonpolar solvent) had a peak at $467 \mathrm{~nm}$ and humps at 448 and $497 \mathrm{~nm}$; the fluorescence FWHM was $44 \mathrm{~nm}$. The fluorescence spectra of polar protic and nonpolar solvents showed a very similar profile with well distinguishable peak and humps, but for polar aprotic solvents, the profile was broad, the features were not distinctive, and the peak at approximately $430 \mathrm{~nm}$ vanished. It is known that primary vibronic transition (V1) is forbidden when a material forms $\mathrm{H}$-aggregates; hence, the absence of the S0-S1 transition attributes to the formation of $\mathrm{H}$-aggregates in the polar aprotic solvent [36].

\subsection{Absorption and Fluorescence Spectra of CO in Toluene}

The range of concentration used was $485-3.79 \mu \mathrm{M}$, a 128 -fold dilution. The absorption spectrum for higher concentrations $(485-60.63 \mu \mathrm{M})$ was saturated. For concentrations less than $30.31 \mu \mathrm{M}$, the absorption spectra showed three different features as in Figure 7a: a shoulder at a shorter wavelength of approximately $375 \mathrm{~nm}$, a peak at $398 \mathrm{~nm}$, and another shoulder at a longer wavelength of approximately $420 \mathrm{~nm}$. These features are attributed to the vibration band S0-S1 (V1) of the monomer and the vibration band S0-S2 (V2) of the monomer, and the hump at $420 \mathrm{~nm}$ is attributed to the dimer. The ratio vibration peaks of the monomer did not change (i.e., $R_{\frac{375}{398}}=0.69$ ) for all concentrations, hence it should be the vibrational features of the monomer. However, the ratio between the monomer peak at $398 \mathrm{~nm}$ and the dimer at $420 \mathrm{~nm}\left(R_{\frac{420}{398} \mathrm{~nm}}\right)$ is decreased from $93 \%$ to $75 \%$ for the concentrations shown above. This steady decline of the peak absorption with respect to concentration is evidence for the presences of the "dimer" [37]. This aggregation could be explained in terms of $\beta$-phase formation due to the side legs $\left(\mathrm{C}_{8} \mathrm{H}_{17}\right)$ [38]. 


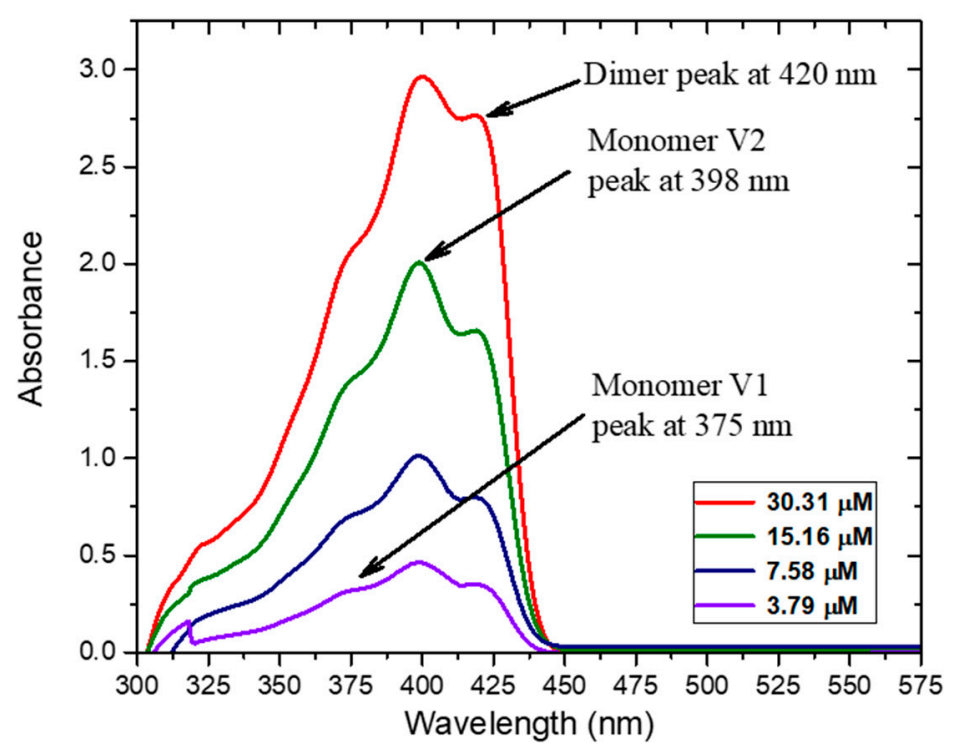

(a)

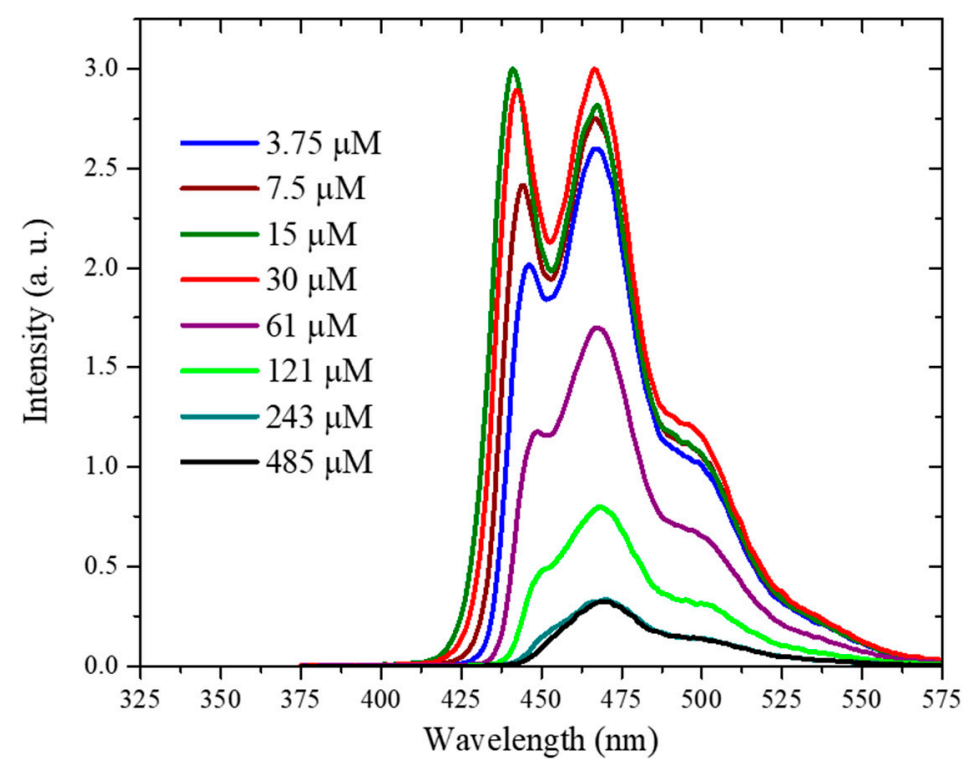

(b)

Figure 7. (a) Absorption spectra of BECV-DHF in toluene for different concentrations. (b) Fluorescence spectra of BECV-DHF in toluene for different concentrations.

Figure $7 \mathrm{~b}$ presents the fluorescence spectra of $\mathrm{CO}$, which display the mirror image to the absorption spectra. It shows two well-defined peaks around 441 and $466 \mathrm{~nm}$, corresponds to the vibrational features V1 and V2 explained in the absorption spectra in Figure 7a. The fluorescence showed a hump at approximately $496 \mathrm{~nm}$, attributed to the dimer. The fluorescence quantum yield of the CO BECV-DHF was calculated in both solutions (toluene and acetone at a concentration of $1.15 \mu \mathrm{M}$ ), and the results were 0.96 and 0.9, respectively. The spectral profile for $\mathrm{CO}$ in acetone is shown in Figure $\mathrm{S} 7$ and points to the formation of $\mathrm{H}$-aggregates.

\subsection{ASE (Mirrorless Laser) from CO BECV-DHF in Toluene and Acetone}

The laser spectra for the CO in many solvents were obtained. The importance of this oligomer arises from a rare property that it can produce ASE from both polar and nonpolar solvents. Hence, 
we describe the photophysical properties of this oligomer in two different categories of the solvents acetone (polar, aprotic) and toluene (nonpolar). The CO kept in toluene at a concentration of $485 \mu \mathrm{m}$ was transverse-pumped with an energy of $0.3 \mathrm{~mJ}$ to obtain laser-induced fluorescence (LIF) with an FWHM of $54 \mathrm{~nm}$. When the pump energy (PE) was increased to $0.5 \mathrm{~mJ}$, a spectral narrowing of $18 \mathrm{~nm}$ occurred. A further increase in PE $(0.8 \mathrm{~mJ})$ produced an efficient ASE peak at $464 \mathrm{~nm}$ with an FWHM of $7.4 \mathrm{~nm}$, and the divergence of the narrow beam was 5 milliradians (mr), as shown in Figure $8 \mathrm{a}$. Hence, this $\mathrm{CO}$ has a four-level laser system permitting a low-threshold process.

In the case of longitudinal pumping, the concentration of the solution was six times lower than that of the transverse $(60.63 \mu \mathrm{M})$ to allow deeper penetration of the pump beam and to avoid strong reabsorption due to attenuation of the active medium. The minimum pump energy for laser action was $1.6 \mathrm{~mJ}$; the ASE had an FWHM of $6 \mathrm{~nm}$. When the pump energy increased to $2.5 \mathrm{~mJ}$, a very narrow ASE spectrum was produced with an FWHM of $3.5 \mathrm{~nm}$, as presented in Figure 8a. The low threshold is could be due to efficient waveguiding and small feedback from the faces of the cuvette. The narrow emission of the CO in the longitudinal pump (LP) indicates that it is an auspicious material for an optical diode-pumped solid-state laser.

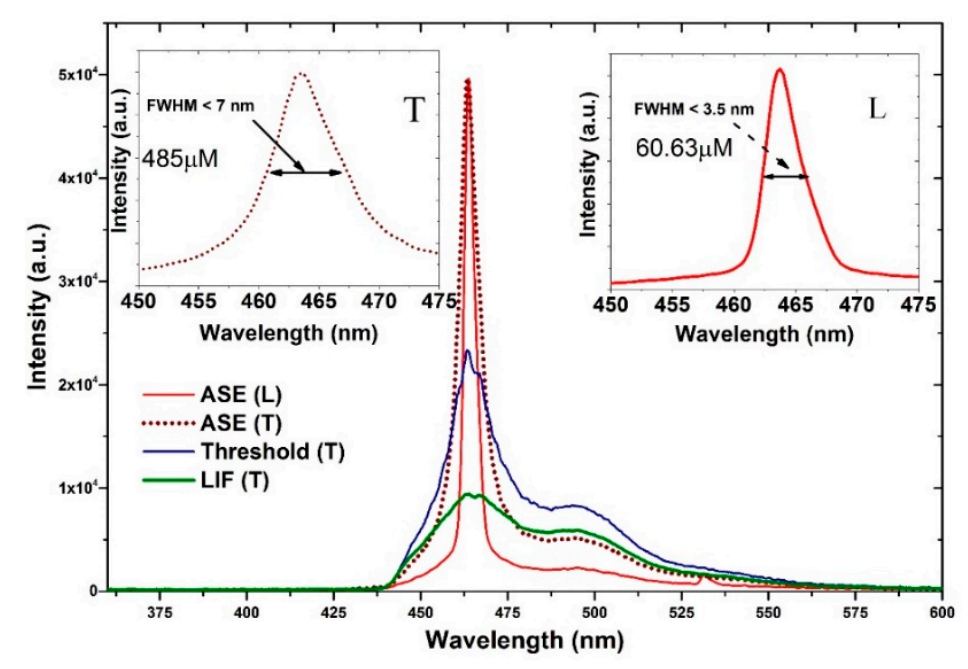

(a)

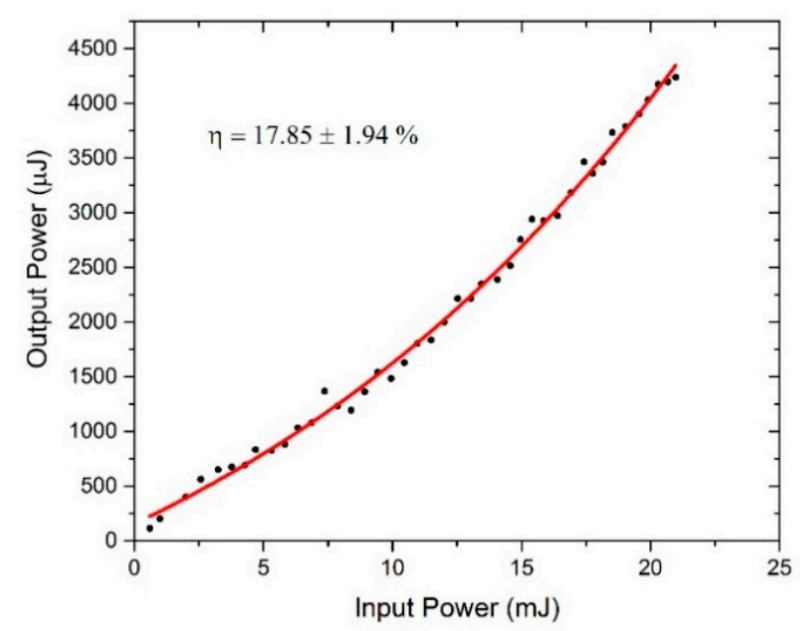

(b)

Figure 8. Cont. 


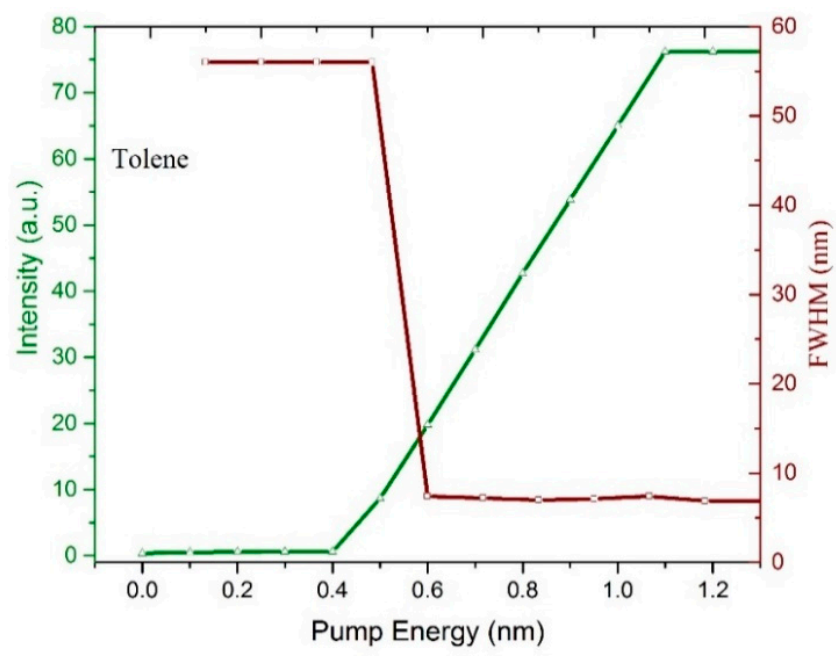

(c)

Figure 8. (a) ASE, threshold and laser-induced fluorescence (LIF) spectra of CO in toluene, (b) efficiency of CO ASE in toluene with input energy $(\mathrm{mJ})$ versus output energy $(\mu \mathrm{J})$, and $(\mathbf{c})$ relationship between pump energy, intensity, and full-width half maximum (FWHM) of ASE in toluene.

Figure $8 \mathrm{~b}$ shows the relationship between input and output energy in toluene. The CO showed an efficiency of $17.85 \% \pm 1.94 \%$, with the maximum being $19.79 \%$. This is due to the high optical gain coefficient, large gain cross-section, and low reabsorption of the $\mathrm{CO}$. Figure $8 \mathrm{c}$ shows the spectra narrowing and rapid increase in intensity with respect to the increase in the pump energy (for TP). At $0.5 \mathrm{~mJ}$, the FWHM dropped from 40 to $7 \mathrm{~nm}$ and the intensity increased to higher values. A further increase in pump energy increased the output intensity, but the FWHM of ASE was maintained. The decrease in linewidth took place because the net gain was maximal near the vibronic transition peaks of the Fluorescence spectrum (FLS); hence, the spectrum displayed gain narrowing as the pump energy increased.

Figure 9a shows the spectral response of the $\mathrm{CO}$ in acetone (a polar aprotic solvent) at the same concentration for transverse TP $(485 \mu \mathrm{M})$ and longitudinal LP $(60.63 \mu \mathrm{M})$, respectively. The threshold for TP was $1.2 \mathrm{~mJ}$, which is twice that of the toluene environment. The FWHM was $8 \mathrm{~nm}$ broader $(\sim 1 \mathrm{~nm})$ than the CO in toluene. Similarly, for LP, the FWHM was $5 \mathrm{~nm}$ and the minimum pump energy for laser action was $2.5 \mathrm{~mJ}$. The ASE efficiency was $9.65 \% \pm 1.94 \%$, with a maximum $\eta$ of $11.04 \%$ as shown in Figure 9b. The relationship between pump energy, the narrowing of FWHM, and rapid increase in ASE intensity is shown in Figure 9c, at approximately $1.5 \mathrm{~mJ}$ the FWHM dropped from 74 to $8 \mathrm{~nm}$ and the intensity increased to higher values. Due to high polarity, volatility, and plasma production the ASE in an acetone environment is rarely reported. However, the CO produces a very stable ASE output, when the solution is maintained at a low temperature $\left(5^{\circ} \mathrm{C}\right)$. The $\mathrm{CO}$ dissolved in the polar solvent through the high polarizability around the nitrogen atom of 9-ethyl-9H-carbazole segments, as shown in Figure S1. 


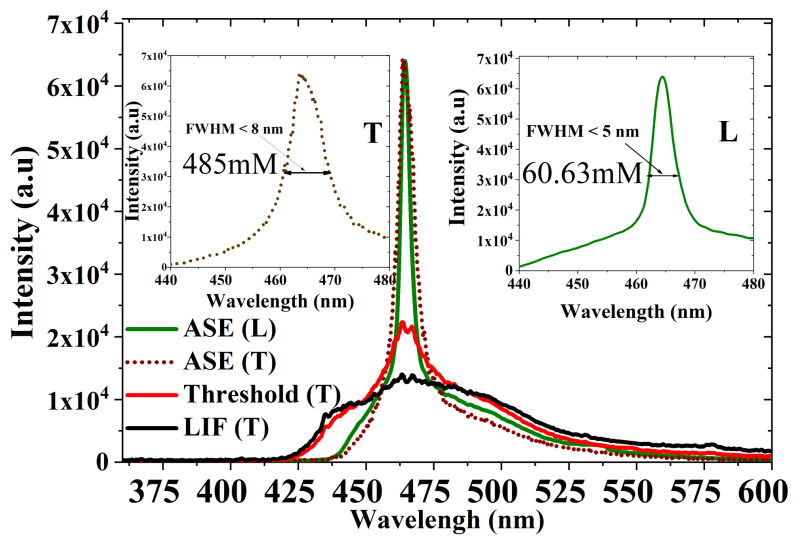

(a)

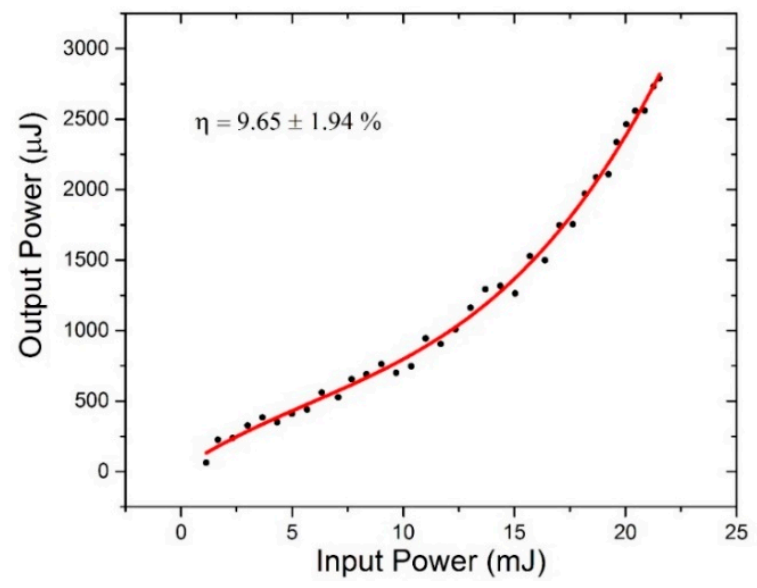

(b)

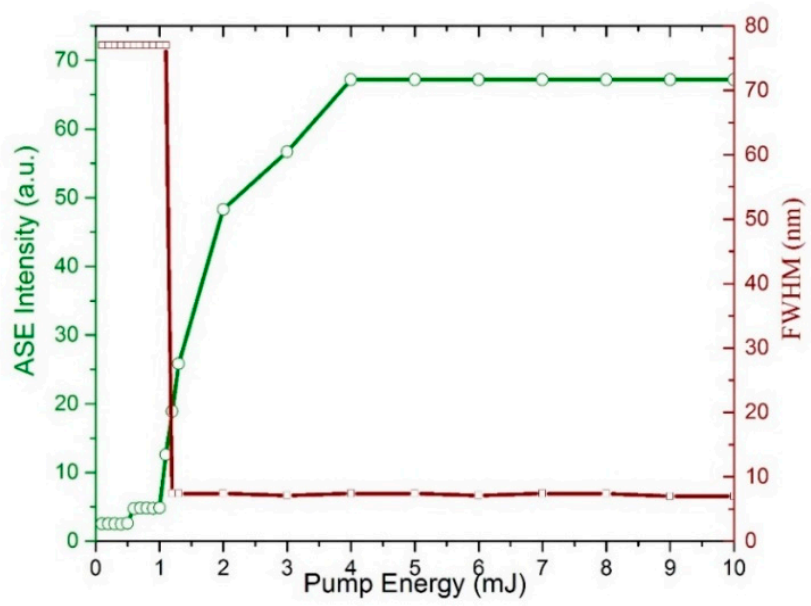

(c)

Figure 9. (a) Amplified spontaneous emission (ASE), threshold, and LIF Spectra of CO in acetone, (b) efficiency of CO ASE in acetone with input energy $(\mathrm{mJ})$ versus output energy $(\mu \mathrm{J})$, and (c) relationship between pump energy, intensity, and FWHM of ASE in acetone. 


\subsection{TRS of the CO BECV-DHF in Toluene}

Even though we studied the sub-nanosecond time dynamics of $\mathrm{CO}$ in various solutions, we present only the dynamics of $\mathrm{CO}$ in toluene solutions under TP. Figure 10 shows the TRS spectra of $\mathrm{CO}$ in toluene, at a low pump energy of $1.25 \mathrm{~mJ}$ and concentration of $485 \mu \mathrm{M}$; it took $25 \mathrm{~ns}$ from the trigger to start fluorescence. However, due to the high gain cross-section, the CO produced ASE in the next 1 $\mathrm{ns}$, and the high-intensity ASE was abruptly stopped within $3 \mathrm{~ns}$, due to the rapid depletion of the excited state species through stimulated emission. For the next 2 ns, a momentary blink (no ASE) occurred, during which the trailing edge of the pump pulse excited the ground state species and ASE was produced in a constant phase and completely decayed. A weak fluorescence due to the relaxation process was produced at approximately $49 \mathrm{~ns}$. This dynamic shows that this $\mathrm{CO}$ is capable of rapid excitation and fluorescence processes.

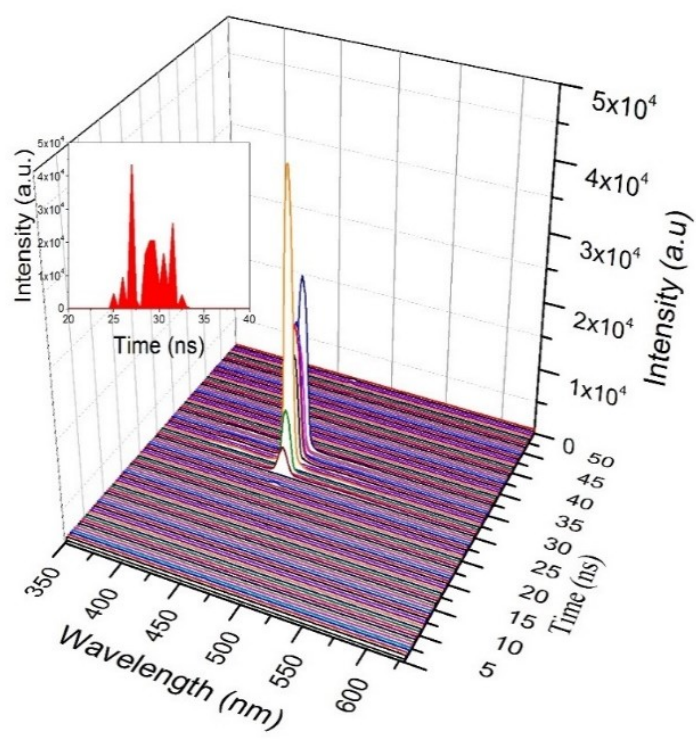

Figure 10. Time dynamics of $\mathrm{CO}$ in toluene at pump energy of $1.25 \mathrm{~mJ}$ and concentration of $485 \mu \mathrm{M}$.

Figure 11a shows the time-dependent response of the $\mathrm{CO}$ in toluene at a concentration of $485 \mu \mathrm{M}$ for TP with pump energy of $4 \mathrm{~mJ}$. The ASE produced by the CO was temporally Gaussian, with a deviation with $96 \% \pm 1 \%$ conformation. Figure $11 \mathrm{~b}$ shows the actual ASE output (peak intensity at $464 \mathrm{~nm}$ ) and a smoothed average of the same (5-point adjacent average) to visualize the near-Gaussian temporal ASE profile. The CO process temporal self-beam shaping ability due to second-order nonlinear effects. The experimental results indicate that the pump beam excites the continuous and that simulated emission was also maintained at a constant rate. This phenomenon shows that this CO at this concentration in toluene forms a perfect four-state laser, which is suitable as a continuous wave laser, a property yet to be explored.

The temporally Gaussian ASE was produced for a range of pump energy of 1.5-6 mJ. This rare phenomenon of temporal Gaussian ASE shows the high efficiency of this CO.

Figure 12a shows the time dynamics of $\mathrm{CO}$ in toluene at the above-discussed concentration, but the pump energy was increased above $6 \mathrm{~mJ}$. When the pump energy was $12 \mathrm{~mJ}$, due to high photon flux, the temporal Gaussian shape of the output pulse was slightly modified, the ASE attained the peak in the rapid phase, momentarily dropped to less than half of its strength, and started again and stabilized for approximately $4 \mathrm{~ns}$; finally, the primary pulse rapidly fell. However, after $5 \mathrm{ns,}$ the secondary ASE appeared with a much weaker intensity and had a miniature image of the primary pulse. This is an indication of nanosecond relaxation due to high photon flux and excited state absorption [39]. The actual and average temporal profile of the peak ASE wavelength is depicted in Figure 12b. Figure 12b shows the actual ASE output (peak intensity at $464 \mathrm{~nm}$ ) (blue shape) and 
smoothed average of the same (5-point adjacent average) (red shape) to visualize the near-Gaussian temporal ASE profile.

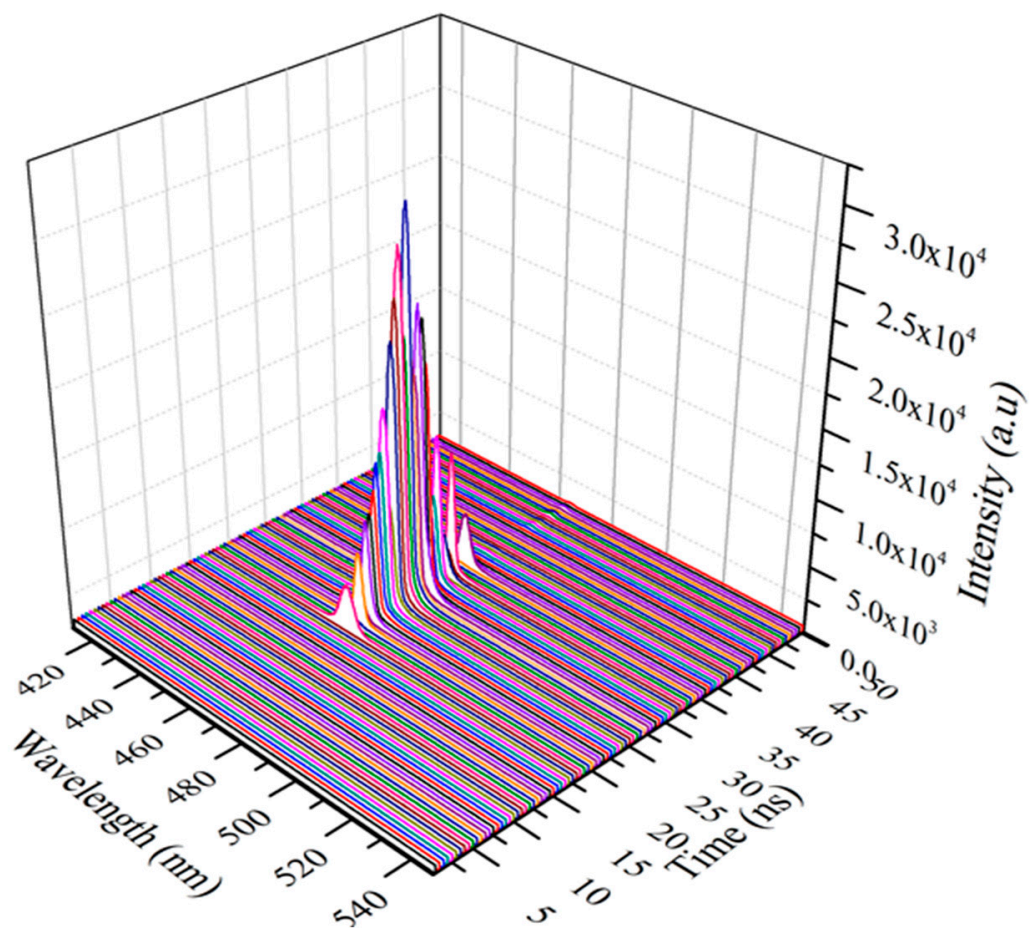

(a)

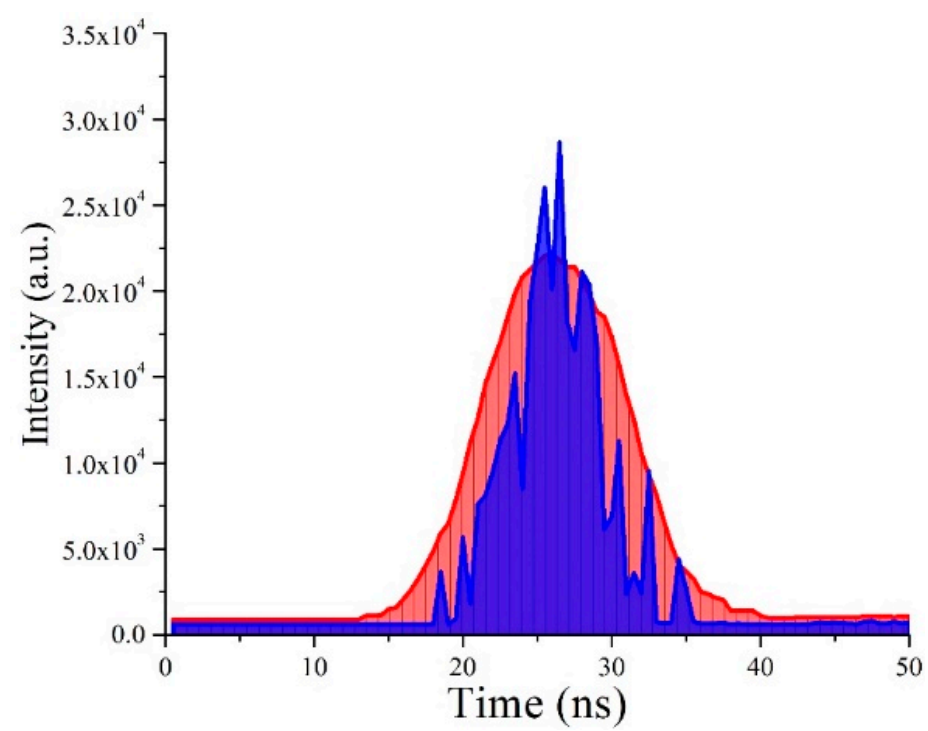

(b)

Figure 11. (a) Time dynamics of CO in toluene at pump energy of $4 \mathrm{~mJ}$ and concentration of $485 \mu \mathrm{M}$ and (b) average temporal profile of the peak ASE wavelength. 


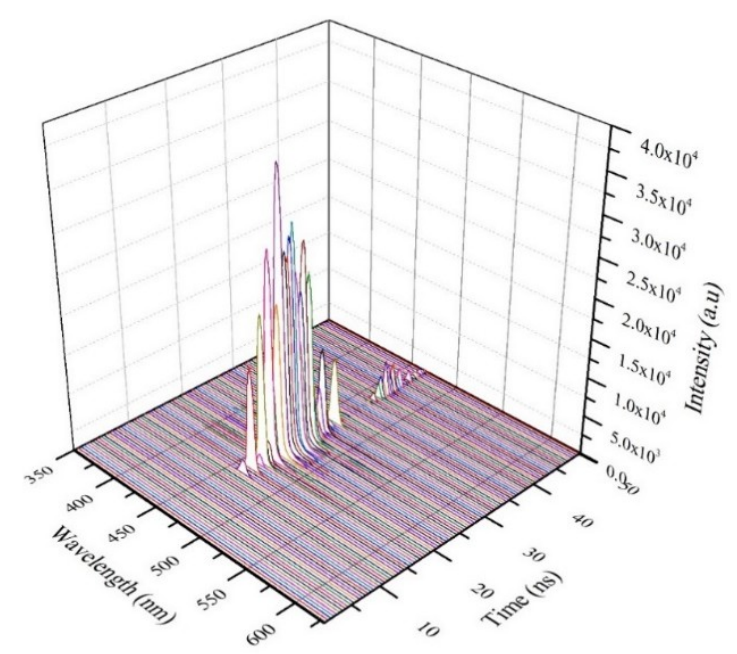

(a)

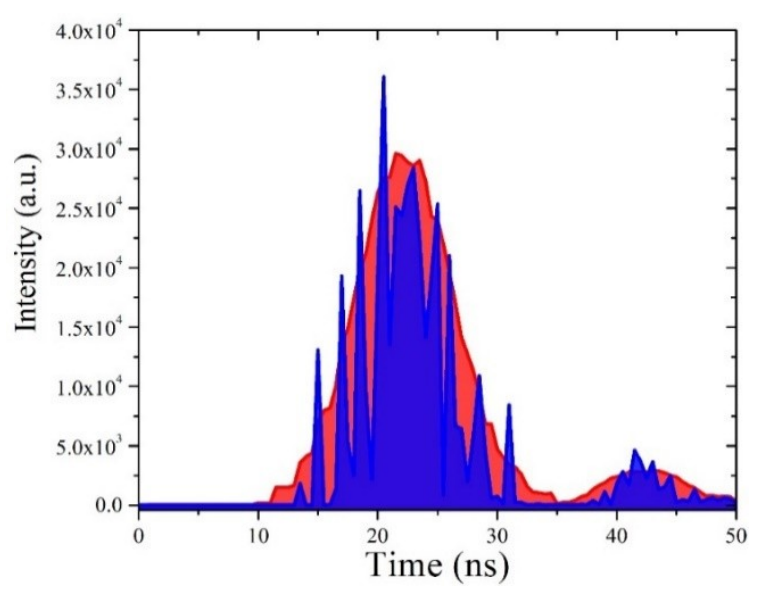

(b)

Figure 12. (a) Time dynamics of $\mathrm{CO}$ in toluene at pump energy of $12 \mathrm{~mJ}$ and concentration of $485 \mu \mathrm{M}$ and $(\mathbf{b})$ average temporal profile of the peak ASE wavelength at a pump energy of $12 \mathrm{~mJ}$.

The Gaussian profile became sharp with abrupt blinks, and the peak intensity was attained faster and not in the middle. The excess energy stored in the excited state gave rise to a strong fluorescence relaxation. The profile of the relaxation was almost the same as the primary fluorescence but with only a fraction of the intensity.

Figure 13 show the consequence of high photon flux (i.e., high pump energy). In the four-level system, this oligomer can only handle pump energy up to a certain level (up to $18 \mathrm{~mJ}$ ) in toluene. The pump energy was increased to a higher level (in this case $25 \mathrm{~mJ}$ ), and the equilibrium between the excitation and de-excitation (radiative and nonradiative pathways) was disturbed. As a result, the smooth temporal Gaussian output of ASE was distorted. The excited-state absorption process took place and gave rise to relaxation after 4-6 ns after the primary ASE. However, this relaxation is considered to be a loss as most of the excited species relaxed through a nonradiative process. 


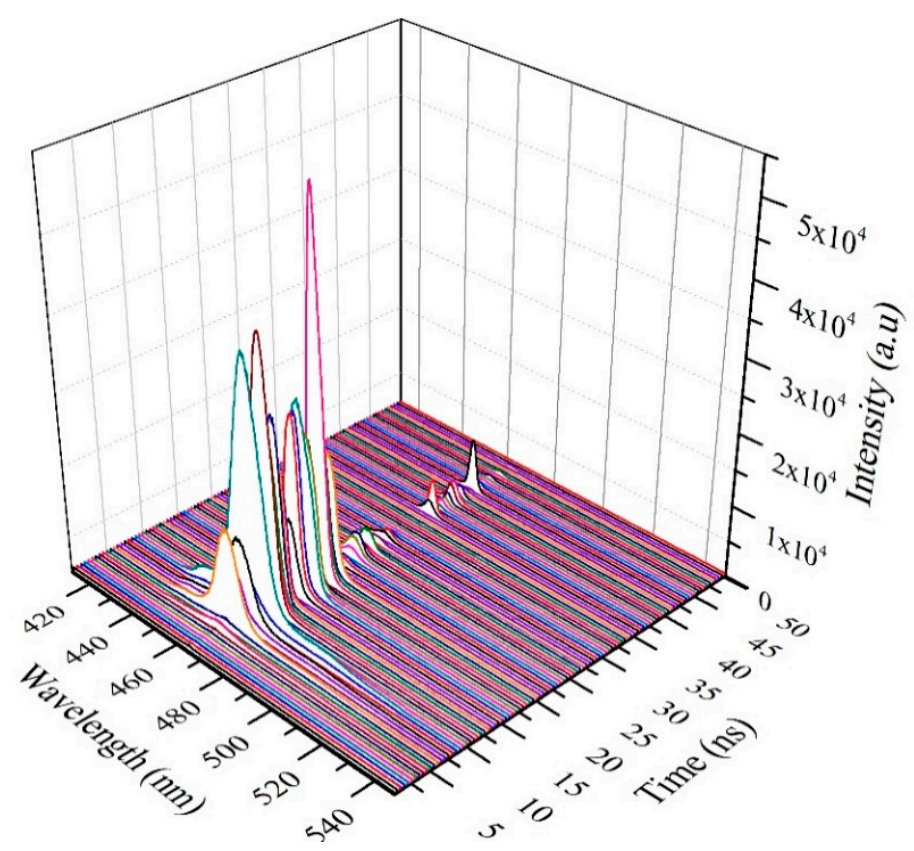

Figure 13. Time dynamics of $\mathrm{CO}$ under high pump energy ( $25 \mathrm{~mJ})$.

\section{ASE Stability}

The ASE stability of BECV-DHF (CO) and a conjugated polymer (CP) (PFO-co-pX) in toluene was measured and compared as shown in Figure 14. Both CO and CP were kept at a concentration of $250 \mu \mathrm{M}$, and the pump energy was $20 \mathrm{~mJ}$. The output of $\mathrm{CO}$ was five times higher than $\mathrm{CP}$. After one hundred thousand $\left(10^{5}\right)$ shots, the output of the $\mathrm{CO}$ was almost the same, but the macromolecule with a very similar chemical structure (at monomer level) suffered $90 \%$ damage to its performance.

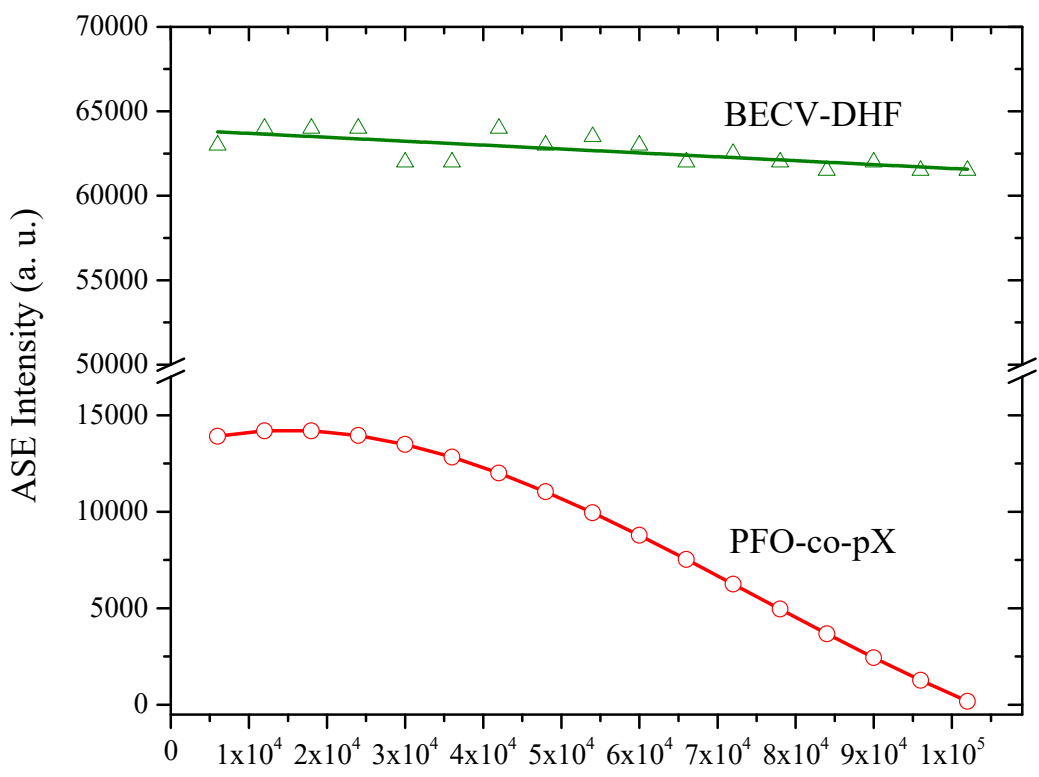

No. of Pulses

Figure 14. The photochemical stability of BECV-DHF and PFO-co-pX at a concentration of $250 \mu \mathrm{M}$.

\section{Conclusions}

In this study, a high-efficient laser material was studied theoretically and experimentally with results that were in agreement with each other. The oligomer was soluble in many solvents, both in 
polar and nonpolar solvents due to the presence of carbazoles and the 9,9-dihexyl group, respectively. The molecule was designed to be planar, and fluorine groups contributed to the laser efficiency. The ASE was produced in most of the solvents, except methanol, ethylene glycol, and few others due to low aromaticity or aprotic polarity (for the concentration and pump energy studied in this work). The maximum efficiency was found to be $20 \%$ in toluene. The time-resolved spectra revealed the excellent temporal Gaussian ASE for the first time in oligomers. The optimal range for the oligomer to produce ASE without disturbing the equilibrium between excitation and de-excitation was $1.5-18 \mathrm{~mJ}$. Any increase in pump energy produced irregular ASE amplitudes and induced strong relaxation.

Supplementary Materials: The following are available online at http://www.mdpi.com/2073-4360/11/10/1534/s1. Figure S1: (a) polarizability of CO BECH-DHF side view and (b) polarizability of CO BECH-DHF top view, Figure S2: The vibration of frequencies $1230-1240 \mathrm{~cm}^{-1} \mathrm{C}=\mathrm{C}$ and $\mathrm{C}-\mathrm{C}$ stretching mode in rings, Figure S3: The vibration of frequencies $1230-1240 \mathrm{~cm}^{-1} \mathrm{C}=\mathrm{C}, \mathrm{C}-\mathrm{C}$ stretching mode in rings and C-H bending, Figure S4: The vibration of $748 \mathrm{~cm}^{-1}$ (T) [i.e., $742 \mathrm{~cm}^{-1}$ (E)] C=C and C-C stretching mode in rings, Figure S5: optical energy gap by crossing the absorption and fluorescence spectra for $\mathrm{CO}$ in toluene (the concentration was $0.235 \mu \mathrm{M}$ ), Figure S6: optical energy gap by crossing the absorption and fluorescence spectra for CO in acetone (the concentration was $0.235 \mu \mathrm{M})$, Figure S7: Absorption and fluorescence spectra of BECV-DHF in Acetone for different concentrations.

Author Contributions: M.A.J., S.P. contributed equally to this work. M.A.S. and Z.A.A. led the work; M.A.J. and S.P. were responsible for the spectral and laser studies of the material; M.A.J., S.P. and M.M.A.-M. did the theoretical studies. M.A.J. and S.P. discussed and analyzed the results and wrote the manuscript. M.A.S., Z.A.A., and M.M.A.-M. managed and approved the manuscript.

Funding: This research was funded by Vice Deanship of Scientific Research Chairs, Deanship of Scientific Research, King Saud University.

Acknowledgments: The authors are grateful to the Deanship of Scientific Research, King Saud University, for funding through the Vice Deanship of Scientific Research Chairs.

Conflicts of Interest: The authors declare no conflict of interest.

\section{References}

1. Kranzelbinder, G.; Leising, G. Organic solid-state lasers. Rep. Prog. Phys. 2000, 63, 729. [CrossRef]

2. Samuel, I.D.W.; Turnbull, G.A. Organic semiconductor lasers. Chem. Rev. 2007, 107, 1272-1295. [CrossRef] [PubMed]

3. Hide, F.; DÍaz-GarcÍa, M.A.; Schwartz, B.J.; Heeger, A.J. New developments in the photonic applications of conjugated polymers. Acc. Chem. Res. 1997, 30, 430-436. [CrossRef]

4. Hide, F.; Diaz-Garcia, M.A.; Schwartz, B.J.; Andersson, M.R.; Pei, Q.; Heeger, A.J. Semiconducting polymers: A new class of solid-state laser materials. Science 1996, 273, 1833-1836. [CrossRef]

5. Friend, R.; Gymer, R.; Holmes, A.; Burroughes, J.; Marks, R.; Taliani, C.; Bradley, D.; Dos Santos, D.; Brédas, J.L.; Lögdlund, M.; et al. Electroluminescence in conjugated polymers. Nature 1999, 397, 121. [CrossRef]

6. Xia, R.; Heliotis, G.; Hou, Y.; Bradley, D.D. Fluorene-based conjugated polymer optical gain media. Org. Electron. 2003, 4, 165-177. [CrossRef]

7. Tessler, N.; Denton, G.; Friend, R. Lasing from conjugated-polymer microcavities. Nature 1996, $382,695$. [CrossRef]

8. Moses, D. High quantum efficiency luminescence from a conducting polymer in solution: A novel polymer laser dye. Appl. Phys. Lett. 1992, 60, 3215-3216. [CrossRef]

9. Kozlov, V.; Forrest, S. Lasing action in organic semiconductor thin films. Curr. Opin. Solid State Mater. Sci. 1999, 4, 203-208. [CrossRef]

10. Pei, Q.; Yu, G.; Zhang, C.; Yang, Y.; Heeger, A.J. Polymer light-emitting electrochemical cells. Science 1995, 269, 1086-1088. [CrossRef]

11. Fish, D.; Young, N.; Childs, M.; Steer, W.; George, D.; McCulloch, D.; Godfrey, S.; Trainer, M.; Johnson, M.; Giraldo, A. 32.1: Invited paper: A comparison of pixel circuits for active matrix polymer/organic LED displays. SID Symp. Digest Tech. Pap. 2002, 33, 968-971. [CrossRef]

12. Li, G.; Zhu, R.; Yang, Y. Polymer solar cells. Nat. Photonics 2012, 6, 153. [CrossRef] 
13. Hoppe, H.; Sariciftci, N.S. Polymer solar cells. In Photoresponsive Polymers II; Springer: Berlin/Heidelberg, Germany, 2007; pp. 1-86.

14. Kawase, T.; Sirringhaus, H.; Friend, R.H.; Shimoda, T. Inkjet Printed Via-Hole Interconnections and Resistors for All-Polymer Transistor Circuits. Adv. Mater. 2001, 13, 1601-1605. [CrossRef]

15. Ahles, M.; Hepp, A.; Schmechel, R.; von Seggern, H. Light emission from a polymer transistor. Appl. Phys. Lett. 2004, 84, 428-430. [CrossRef]

16. Lai, W.Y.; Xia, R.; He, Q.Y.; Levermore, P.A.; Huang, W.; Bradley, D.D. Enhanced Solid-State Luminescence and Low-Threshold Lasing from Starburst Macromolecular Materials. Adv. Mater. 2009, 21, 355-360. [CrossRef]

17. Alsalhi, M.; Ibnaouf, K.; Masilamani, V.; Yassin, O. Excimer state of a conjugate polymer (MEH-PPV) in liquid solutions. Laser Phys. 2007, 17, 1361-1366. [CrossRef]

18. AlSalhi, M.S.; Almotiri, A.R.; Prasad, S.; Aljaafreh, M.J.; Othman, A.H.; Masilamai, V. A Temperature-Tunable Thiophene Polymer Laser. Polymers 2018, 10, 470. [CrossRef]

19. Abdulaziz Alfahd, S.; Prasad Rajendra, S.; Al-Mujammi, W.; Devaraj, D.; Masilamani, V.; AlSalhi, M. An Efficient Violet Amplified Spontaneous Emission (ASE) from a Conjugated Polymer (PFO-co-pX) in Solution. Materials 2017, 10, 265. [CrossRef]

20. Müllen, K.; Wegner, G. Electronic Materials: The Oligomer Approach; John Wiley \& Sons: Hoboken, NJ, USA, 2008.

21. Sperling, L.H. Introduction to Physical Polymer Science; Wiley Online Library: Hoboken, NJ, USA, 2006; Volume 78.

22. Brazel, C.S.; Rosen, S.L. Fundamental Principles of Polymeric Materials; John Wiley \& Sons: Hoboken, NJ, USA, 2012.

23. Prasad, S.; Ibnaouf, K.; AlSalhi, M.; Devaraj, D.; Masilamani, V. High power amplified spontaneous emission from an oligomer in solution. J. Lumin. 2015, 168, 109-113. [CrossRef]

24. Pisignano, D.; Anni, M.; Gigli, G.; Cingolani, R.; Zavelani-Rossi, M.; Lanzani, G.; Barbarella, G.; Favaretto, L. Amplified spontaneous emission and efficient tunable laser emission from a substituted thiophene-based oligomer. Appl. Phys. Lett. 2002, 81, 3534-3536. [CrossRef]

25. Guilhabert, B.; Laurand, N.; Herrnsdorf, J.; Chen, Y.; Mackintosh, A.R.; Kanibolotsky, A.L.; Gu, E.; Skabara, P.J.; Pethrick, R.; Dawson, M.D. Amplified spontaneous emission in free-standing membranes incorporating star-shaped monodisperse $\pi$-conjugated truxene oligomers. J. Opt. 2010, 12, 035503. [CrossRef]

26. Nagawa, M.; Hibino, R.; Hotta, S.; Yanagi, H.; Ichikawa, M.; Koyama, T.; Taniguchi, Y. Emission gain narrowing from single crystals of a thiophene/phenylene co-oligomer. Appl. Phys. Lett. 2002, 80, 544-546. [CrossRef]

27. McGehee, M.D.; Heeger, A.J. Semiconducting (conjugated) polymers as materials for solid-state lasers. Adv. Mater. 2000, 12, 1655-1668. [CrossRef]

28. Aljaafreh, M.J.; Prasad, S.; AlSalhi, M.S.; Alahmed, Z.A. Ultrafast dynamics of laser from green conjugated-oligomer in solution. Polymer 2019, 169, 106-114. [CrossRef]

29. Shimizu, K.; Mori, Y.; Hotta, S. Laser oscillation from hexagonal crystals of a thiophene/phenylene co-oligomer. J. Appl. Phys. 2006, 99, 063505. [CrossRef]

30. Mizuno, H.; Maeda, T.; Yanagi, H.; Katsuki, H.; Aresti, M.; Quochi, F.; Saba, M.; Mura, A.; Bongiovanni, G.; Sasaki, F. Optically Pumped Lasing from Single Crystals of a Cyano-Substituted Thiophene/Phenylene Co-Oligomer. Adv. Opt. Mater. 2014, 2, 529-534. [CrossRef]

31. Frisch, M.J.; Trucks, G.W.; Schlegel, H.B.; Scuseria, G.E.; Robb, M.A.; Cheeseman, J.R.; Scalmani, G.; Barone, V.; Mennucci, B.; Petersson, G.; et al. Gaussian09, Revision A; Gaussian. Inc.: Wallingford, CT, USA, 2009; Volume 121, pp. 150-166.

32. Ullah, H.; Shah, A.-U.-H.A.; Ayub, K.; Bilal, S. Density functional theory study of poly (o-phenylenediamine) oligomers. J. Phys. Chem. C 2013, 117, 4069-4078. [CrossRef]

33. Renzi, W.; Cordeiro, N.J.; de Santana, H.; Costa, M.F.; da Silva, M.A.; Laureto, E.; Duarte, J.L. Exploring the experimental photoluminescence, Raman and infrared responses and density functional theory results for TFB polymer. Synth. Met. 2018, 236, 24-30. [CrossRef]

34. Bencheikh, F.; Duché, D.; Ruiz, C.M.; Simon, J.-J.; Escoubas, L. Study of optical properties and molecular aggregation of conjugated low band gap copolymers: PTB7 and PTB7-Th. J. Phys. Chem. C 2015, 119, 24643-24648. [CrossRef] 
35. Justino, L.L.; Luísa Ramos, M.; Abreu, P.; Charas, A.; Morgado, J.; Scherf, U.; Minaev, B.F.; Ågren, H.; Burrows, H.D. Structural and electronic properties of poly (9, 9-dialkylfluorene)-based alternating copolymers in solution: An NMR spectroscopy and density functional theory study. J. Phys. Chem. C 2013, 117, 17969-17982. [CrossRef]

36. Hestand, N.J.; Spano, F.C. Expanded theory of H-and J-molecular aggregates: The effects of vibronic coupling and intermolecular charge transfer. Chem. Rev. 2018, 118, 7069-7163. [CrossRef] [PubMed]

37. Quan, S.; Teng, F.; Xu, Z.; Qian, L.; Hou, Y.; Wang, Y.; Xu, X. Solvent and concentration effects on fluorescence emission in MEH-PPV solution. Eur. Polym. J. 2006, 42, 228-233. [CrossRef]

38. Dias, F.B.; Morgado, J.; Macanita, A.L.; da Costa, F.P.; Burrows, H.D.; Monkman, A.P. Kinetics and thermodynamics of poly (9,9-dioctylfluorene) $\beta$-phase formation in dilute solution. Macromolecules 2006, 39, 5854-5864. [CrossRef]

39. Mujamammi, W.; Prasad, S.; AlSalhi, M.; Masilamani, V. Relaxation oscillation with picosecond spikes in a conjugated polymer laser. Polymers 2016, 8, 364. [CrossRef] [PubMed]

C 2019 by the authors. Licensee MDPI, Basel, Switzerland. This article is an open access article distributed under the terms and conditions of the Creative Commons Attribution (CC BY) license (http://creativecommons.org/licenses/by/4.0/). 